\title{
EFFECT OF PREOPERATIVE SUPPLEMENTATION WITH $\alpha$-TOCOPHEROL AND ASCORBIC ACID ON MYOCARDIAL INJURY IN PATIENTS UNDERGOING CARDIAC OPERATIONS
}

Justin Westhuyzen, $\mathrm{PhD}$

Andrew D. Cochrane, MBBS, FRACS, FRCS

Peter J. Tesar, MBBS, FRACS

Terrence Mau, MBBS, FRACS

David B. Cross, MBBS, FRACP

Michael P. Frenneaux, MD, MRCP

(UK), FRACP

Frederick A. Khafagi, MBBS

(Hons), FRACP

Simon J. Fleming, MD, FRACP, FRCP

\begin{abstract}
Augmentation of antioxidant defenses may help protect tissues against ischemia-reperfusion injury associated with operations involving cardiopulmonary bypass. In this study we examined the effect of pretreating patients with $\alpha$-tocopherol (vitamin E) and ascorbic acid (vitamin C) or placebo on injury to the myocardium. Seventy-six subjects undergoing elective coronary artery bypass grafting participated in a prospective, double-blind, placebo-controlled randomized trial, receiving either placebo or both $750 \mathrm{IU}$ dl- $\alpha$-tocopherol per day for 7 to 10 days and $1 \mathrm{gm}$ ascorbic acid 12 hours before the operation. Plasma $\alpha$-tocopherol concentrations, raised fourfold by supplementation, fell by $\mathbf{7 0} \%$ after the operation in the supplemented group and to negligible levels in the placebo group. There were no significant differences between the groups with respect to release of creatine kinase $\mathrm{MB}$ isoenzyme over 72 hours, nor in the reduction of the myocardial perfusion defect determined by thallium 201 uptake. Electrocardiography provided no evidence of a benefit from antioxidant supplementation. Thus the supplementation regimen prevented the depletion of the primary lipid soluble antioxidant in plasma, but provided no measurable reduction in myocardial injury after the operation. ( $J$ Thorac Cardiovasc Surg 1997;113:942-8)
\end{abstract}

Castons ardiac surgery with cardiopulmonary bypass (CPB) is associated with the risk of ischemiareperfusion type injury to the myocardium and other tissues, as a result of aortic crossclamping and altered arterial blood flow patterns. Tissue injury may arise during both the period of ischemia and the initial seconds of reperfusion. ${ }^{1}$ In terms of the free radical hypothesis, reperfusion injury results from the production of oxygen-derived free radicals and other reactive oxygen substances in amounts

From the Departments of Cardiology, Pathology, Nuclear Medicine, and Renal Medicine, Royal Brisbane Hospital, and the Department of Cardiac Surgery, The Prince Charles Hospital, Brisbane, Australia.

Supported by grants from The Private Practice Trust Fund, Royal Brisbane Hospital, and The Prince Charles Hospital Private Practice Research \& Education Trust Fund SSAC93/8/05 and L25540.

Received for publication Jan. 29, 1996; revisions requested March 11, 1996; revisions received Nov. 11, 1996; accepted for publication Dec. 9, 1996.

Address for reprints: J. Westhuyzen, PhD, Conjoint Renal Laboratory, Royal Brisbane Hospital, Herston 4029, Brisbane, Australia.

Copyright (C) 1997 by Mosby-Year Book, Inc.

$0022-5223 / 97 \$ 5.00+0 \quad \mathbf{1 2 / 1 / 7 9 7 8 8}$ that overwhelm the body's endogenous antioxidant defenses. The whole-body inflammatory reaction resulting from $\mathrm{CPB}$ contributes to the oxidative stress. Complement-activated neutrophils are a major source of oxidant species ${ }^{1,2}$ and are implicated in microvascular injury and consequent parenchymal organ injury. 1,3

Evidence for myocardial reperfusion injury induced by oxygen-derived free radicals has been largely derived from animal models and in vitro perfused hearts; studies in human beings are limited ${ }^{4-8}$ Recently, it has been reported that myocardial reperfusion after aortic crossclamping in human beings leads to increases in markers of free radical activity, such as lipid peroxidation, ${ }^{9-11}$ and a decrease in myocardial concentrations of the major membrane antioxidant $\alpha$-tocopherol. ${ }^{12}$ Studies showing a protective effect of allopurinol, an inhibitor of xanthine oxidase (which catalyzes the production of superoxide radicals) during coronary artery bypass grafting $(\mathrm{CABG})$ are consistent with the notion of oxidative stress during reoxygenation. ${ }^{6,13,14}$

There are a number of theoretic approaches to limiting the toxic effects of oxygen-derived free radicals in vivo. ${ }^{3}$ One is to augment the body's antioxidant defenses before surgery. ${ }^{15}$ The primary 
physiologic antioxidants are the lipid-soluble, chainbreaking vitamin $\alpha$-tocopherol (vitamin $\mathrm{E}$ ) and, in the aqueous phase, ascorbic acid (vitamin C) and glutathione. ${ }^{16}$ Initial studies suggest that pretreatment of patients undergoing $\mathrm{CPB}$ with $\alpha$-tocopherol or ascorbic acid reduces lipid peroxidation (malondialdehyde production) and myocardial tissue injury (enzyme efflux) during CPB. ${ }^{8,9,17,18}$ However, the potential benefit of antioxidant administration, and especially of $\alpha$-tocopherol, on ischemia-reperfusion injury in vivo is controversial.

The present study was undertaken to determine the effect of pretreating patients undergoing CPB with both $\alpha$-tocopherol and ascorbic acid or placebo on markers of myocardial injury after CPB. Inasmuch as $\alpha$-tocopherol is relatively poorly absorbed, dietary supplementation was extended to 7 to 10 days before the operation to augment both its circulating and tissue concentrations. ${ }^{8,} 19$ Ascorbic acid, on the other hand, is readily absorbed and distributed to tissues. Because ascorbic acid may be involved in the regeneration of $\alpha$-tocopherol from its $\alpha$-tocopheroxyl radical, ${ }^{20}$ supplementation with both antioxidants was used to maximize antioxidant protection after $\mathrm{CPB}$.

\section{Methods}

Patients. Patients undergoing CABG were admitted to the trial if the following criteria were met: the patient was aged 18 to 75 years, did not smoke, and gave informed consent more than 10 days before the operation. Patients were excluded if they were receiving coumarin derivatives (very high doses of vitamin E may potentiate anti-vitamin $\mathrm{K}$ therapy), vitamin supplements, or corticosteroids. In addition, malabsorption syndromes, severe asthma, obstructive pulmonary disease, poor left ventricular function (ejection fraction $<40 \%$ ), and a history of alcoholism, drug abuse, psychosis, or a combination of these conditions excluded patients from the study. Eligible patients were then assigned the next available (randomized) study number and accompanying coded treatment.

Seventy-nine patients were enrolled. Three subjects were excluded after randomization because of canceled operations (urgent cases took priority over scheduled operations); thus the study finally consisted of 76 patients. Thirty-eight patients were assigned to the vitamin-supplemented (active) group and the same number to the placebo group. The mean age was 59.9 years; 63 of 76 $(82.9 \%)$ were male (Table I).

The study was conducted in accordance with the ethical guidelines of the National Health and Medical Research Council of Australia; the protocol was approved by the Human Ethics Committee of The Prince Charles Hospital, Brisbane.

Intervention (supplementation). Enrolled subjects received a 10-day supply of capsules (active or placebo) for
Table I. Clinical characteristics of patients

\begin{tabular}{|c|c|c|c|}
\hline Parameter & Placebo & Supplemented & Combined \\
\hline Age (mean $\pm \mathrm{SD} ; \mathrm{yr}$ ) & $59.7 \pm 7.7$ & $60.0 \pm 7.0$ & $59.9 \pm 7.3$ \\
\hline Sex ratio (male/female) & $30: 8$ & $33: 5$ & $63: 13$ \\
\hline $\begin{array}{l}\text { Bypass time (median, } \\
\text { first quartile, third }\end{array}$ & 68.0 & 74.0 & 70.5 \\
\hline quartile; $\min$ ) & $50.8,90.0$ & $56.8,107.0$ & $55.0,90.0$ \\
\hline $\begin{array}{l}\text { Crossclamp time (medi- } \\
\text { an, first quartile, third }\end{array}$ & 41.0 & 44.0 & 43.0 \\
\hline quartile; min) & $29.5,55.0$ & $30.8,55.3$ & $30.0,55.0$ \\
\hline No. of grafts $(1 / 2 / 3 / 4 / 5 / 6)$ & $1 / 5 / 11 / 10 / 8 /$ & $10 / 2 / 12 / 12 / 9 / 2$ & $1 / 7 / 23 / 22 / 17 / 3$ \\
\hline
\end{tabular}

$S D$, Standard deviation.

self-administration. The active capsules provided 750 IU dl- $\alpha$-tocopheryl acetate daily; the placebo provided an equivalent amount of sucrose. Compliance was monitored by measuring serum $\alpha$-tocopherol levels and by capsule counts. Twelve hours before the operation, supplemented patients also received $1 \mathrm{gm}$ ascorbic acid orally, and control subjects received a placebo (1 gm sucrose). No side effects attributable to the supplement or placebo were reported.

Surgical procedure. Patients underwent $\mathrm{CABG}$ with standard CPB. In brief, after systemic heparinization, CPB was established with Cobe roller pumps (Cobe Laboratories, Inc., Denver, Colo.), a flat-sheet membrane oxygenator (Cobe) and an arterial filter (Pall Biomedical Products, East Hills, N.Y.). The extracorporeal circuit was primed with 2 L of crystalloid solution (lactated Ringer's solution); packed cells were included if the diluted hematocrit value was expected to fall below 0.20 . Minimum flow rates of $2.4 \mathrm{~L} / \mathrm{min}$ per square meter and core temperatures of $30^{\circ}$ to $32^{\circ} \mathrm{C}$ were maintained throughout CPB. Multidose hypothermic potassium cardioplegic solution and topical hypothermia were used during aortic crossclamping. Median CPB and crossclamp times are shown in Table I.

Sample collection. Peripheral venous blood was collected before the operation and at intervals over the subsequent 72 hours.

Laboratory methods: Plasma creatine kinase isoenzyme $\mathrm{MB}$ (CK-MB) was estimated by electrophoresis by means of the REP CK-8 isoenzyme system (Helena Laboratories, Beaumont, Tex.). Plasma $\alpha$-tocopherol was estimated by ultraviolet detection at $285 \mathrm{~nm}$ after separation by high-performance liquid chromatography. ${ }^{21} \alpha$-Tocopherol acetate served as an internal standard. Because fluid balance is largely restored by 12 hours and because our primary concern was the comparison between patient groups, plasma enzyme and vitamin levels were not corrected for the effect of the crystalloid pump prime.

Electrocardiography. Electrocardiograms were obtained before the operation and at hospital discharge (usually the sixth or seventh day). A 54-criteria QRS scoring system ${ }^{22}$ was used to evaluate the extent of myocardial damage. The theoretic maximal score on this system is 32 points, with each additional point representing a loss of approximately $3 \%$ of left ventricular myocardium. Measurements were made on standard 12-lead 


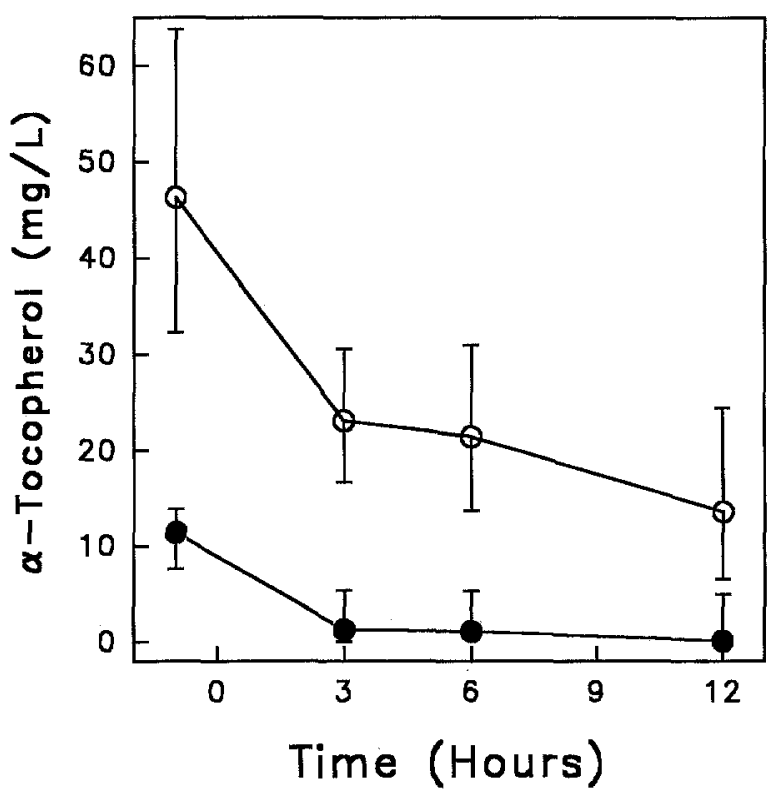

Fig. 1. Changes in plasma $\alpha$-tocopherol concentrations after cardiac surgery (medians and first and third quartiles). The open circles indicate patients receiving supplemental $\alpha$-tocopherol and ascorbic acid, and the solid symbols, the placebo group. The difference between groups, changes with time, and group $\times$ time interaction were all highly significant $(p<0.001)$.

electrocardiograms recorded at a frequency response of 0.05 to $100 \mathrm{~Hz}$ using manual callipers.

Thallium scans. The extent of perioperative segmental myocardial injury was assessed by single-photon emission computed tomographic (SPECT) thallium 201 (Tl-201) scans obtained at rest in the preoperative period and before hospital discharge. Patients underwent the scan if they gave written, informed consent and if the scan could be scheduled during the work week $(n=41)$. Subjects were given an intravenous injection of $80 \mathrm{MBq}$ of Ti-201 at rest after an overnight fast. Within 30 minutes of injection, a SPECT scan was acquired in 32 angles over 180 degrees (right anterior oblique to left posterior oblique). Tomograms were reconstructed by filtered backprojection, with oblique-angle reorientation along the long axis of the left ventricle, and displayed in oblique short-axis and horizontal and vertical long-axis slices. Preoperative and postoperative scan pairs for each patient were compared in the same format as conventional stress/ rest Tl-201 scan pairs, with quantitation of myocardial thallium distribution using a two-dimensional polar map. ${ }^{23}$ Scans were interpreted by an experienced nuclear medicine physician who was blinded to the patient's treatment.

Total defect extent was estimated from the polar map analysis, as the percentage of total left ventricular volume in which Tl-201 uptake (relative to maximal uptake) was more than 2.5 standard deviations below the mean of a gender-specific reference database of resting myocardial
Tl-201 distribution. Defect severity on the tomographic slices was graded for each of five segments (anterior, septal, inferior, lateral, and apical) using a semiquantitative color table, as follows: $0=$ normal; $1=$ mild $([>80 \%$ of maximal uptakel)/questionable defect/probable artifact; $2=$ definite defect ( $50 \%$ to $80 \%$ of maximal uptake); $3=$ severe $(<50 \%$ of maximal uptake). The total score for all five segments was used as a global severity score. In addition, a combined (severity $\times$ extent) score was determined.

Statistics. The present trial of preoperative supplementation with antioxidant vitamins in cardiac surgery involved a renal as well as a cardiac arm; the renal substudy will be reported elsewhere. Sample size determinations and the power calculations were based on renal outcomes. On the basis of log transformed data from the placebo group $(n=38)$, retrospective power calculations showed that a $75 \%$ change in the logged CK-MB area under the curve would be detected with power $=80 \%$ and $\alpha=0.05$ (two-tailed). As a result of substantial skewness of the distributions, values are reported as medians (first quartile, third quartile). Pre-post differences were approximately normally distributed, and consequently differences between the patient groups' time-related data were analyzed by parametric paired $t$ tests or two-way repeatedmeasures analysis of variance, with the use of SPSS-PC+ version 4.0 (SPSS, Inc., Chicago, Ill.). A square root transformation was applied to CK-MB time profiles, QRS scores, and to $\alpha$-tocopherol values because of unequal variances across the groups. For the calculation of the areas under the CK-MB plasma concentration curves, Sigmaplot graphic software (Jandel) was used, with the trapezoidal rule used for unequally spaced $x$ values.

The significance of differences between two data sets was determined by Student's $t$ test or the Mann-Whitney rank sum test for parametric and nonparametric data, respectively. Correlations between variables were sought with the use of the Pearson product moment correlation. A $p$ value $<0.05$ was considered significant.

\section{Results}

There were no differences between the study groups with respect to duration of bypass ( $p=0.37$ ) and total crossclamp times $(p=0.60)$. There was no significant difference in the proportion of patients with crossclamp times greater than 50 minutes $(0.36$ in the supplemented group; 0.30 in the placebo group; $p=0.75$ ). One patient required surgical débridement and rewiring for sternal infection, and another was reintubated and the lungs were ventilated on day 5 . One patient did not regain consciousness and died after the study period.

Plasma $\alpha$-tocopherol concentrations (Fig. 1). Preoperative plasma $\alpha$-tocopherol concentrations were fourfold higher in the supplemented group (medians 44.7 vs $11.4 \mathrm{mg} / \mathrm{L}, p<0.001$ ). Postoperatively, median concentrations in the supplemented group fell by $70 \%$ but remained at or above normal 


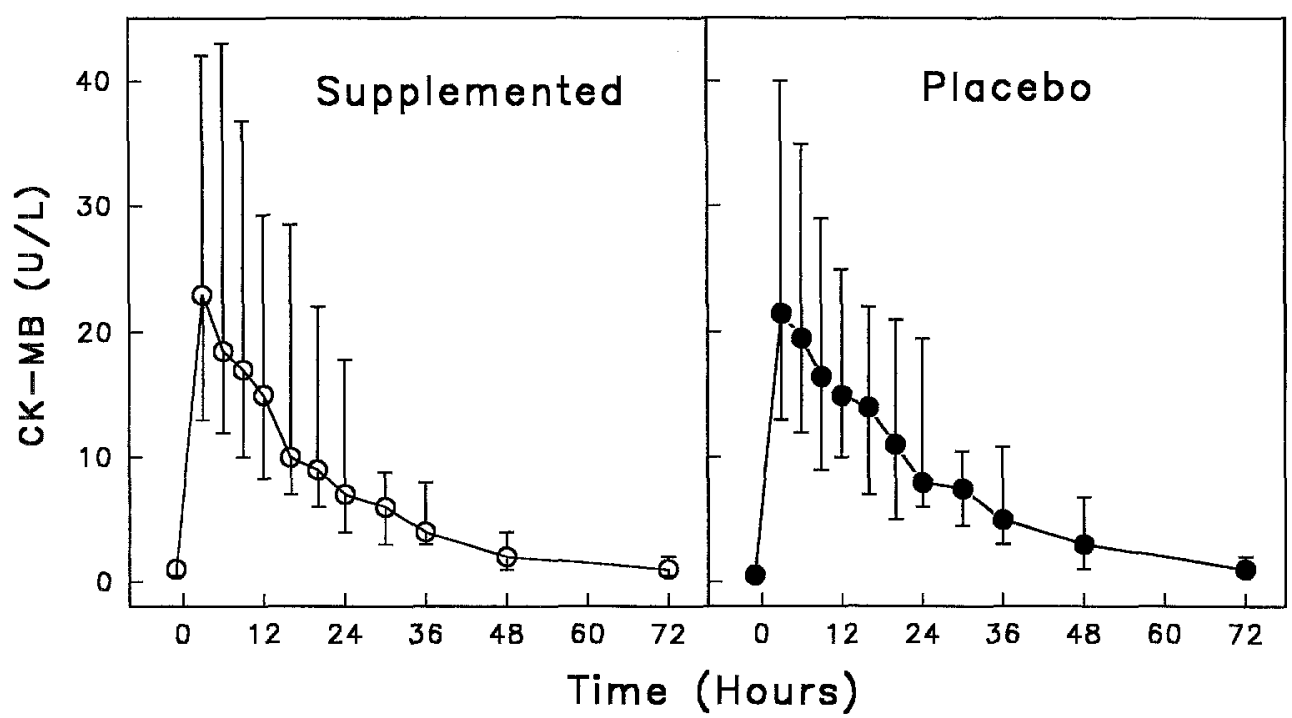

Fig. 2. Changes in plasma CK-MB concentrations after cardiac surgery (medians and first and third quartiles). Laboratory normal reference range, 0 to $10 \mathrm{U} / \mathrm{L}$. The changes with time were highly significant $(p<0.001)$; group $\times$ time interaction, $p=0.47$; difference between groups, $p=0.71$.

Table II. $C K-M B$ release after cardiac operations

\begin{tabular}{ccccccc} 
& \multicolumn{2}{c}{ Placebo group $(n=36)$} & & \multicolumn{2}{c}{ Supplemented group $(n=37)$} \\
\cline { 2 - 3 } Parameter & Median & First, third quartile & & Median & First, third quartile & $p$ Value \\
\hline CK-MB peak $(\mathrm{U} / \mathrm{L})$ & 29 & 16,53 & 28 & 17,43 & 0.81 \\
Area under curve $(\mathrm{U} \cdot \mathrm{hr} / \mathrm{L})$ & 622 & 333,793 & 476 & 299,902 & 0.56 \\
\hline
\end{tabular}

levels. In contrast, concentrations in the placebo group decreased from normal to negligible levels within 3 hours of the operation. The difference between groups, changes with time, and group $\times$ time interaction were all highly significant $(p<$ 0.001 ).

Plasma creatine kinase isoenzymes (Table II and Fig. 2). Changes in plasma CK-MB concentrations with time were highly significant $(p<0.001)$. Median peak values reached were 29 and $28 \mathrm{U} / \mathrm{L}$ in the placebo and supplemented subjects, respectively $(p=0.81)$. There were no significant differences between the groups with respect to CK-MB profiles $(p=0.71)$ nor with respect to CK-MB areas under the curve $(p=0.56)$. The median of the placebo group $(622 \mathrm{U} \cdot \mathrm{hr} / \mathrm{L})$, however, was $23.5 \%$ higher than in the supplemented group $(476 \mathrm{U} \cdot \mathrm{hr} / \mathrm{L})$. The power of the performed test was, however, low (0.37), suggesting that this negative finding be interpreted with caution.
There was no correlation between preoperative plasma $\alpha$-tocopherol levels and the CK-MB area under the curve for the two patient groups considered either separately or collectively or when the combined data were log-transformed $(|r|<0.1, p>$ $0.7)$.

Electrocardiography (Table III). Adequate paired preoperative and postoperative electrocardiograms were available in 49 patients ( 23 placebo, 26 active treatment). Reasons for exclusion from the electrocardiographic analysis included the presence of bundle branch block $(n=12)$ or left ventricular hypertrophy $(n=1)$, inadequate technical quality for analysis $(n=$ $8)$, or death $(n=1)$.

The active treatment group had significantly worse QRS scores than the placebo group at baseline $(p=0.03)$, presumably as a result of chance. Postoperative QRS scores were worse than preoperative scores in the combined group $(p=0.001)$, although the interaction between group and time 
Table III. Extent of myocardial injury determined by QRS score (units)

\begin{tabular}{lccccc}
\hline & $\begin{array}{c}\text { Placebo group } \\
(n=23)\end{array}$ & & $\begin{array}{c}\text { Supplemented group } \\
(n=26)\end{array}$ \\
\cline { 2 - 3 } & Median & $\begin{array}{c}\text { First, } \\
\text { third quartile }\end{array}$ & Median & $\begin{array}{c}\text { First, } \\
\text { third quartile }\end{array}$ \\
\hline Preoperative & 0 & 0,1 & & 1 & 0,3 \\
Postoperative & 1 & 0,2 & & 4 & 1,8 \\
Change & 0 & 0,2 & & 0 & 0,3 \\
\hline
\end{tabular}

Between-group comparison: $p=0.008$; changes with time: $p=0.001$; group $\times$ time interaction: $p=0.92$.

was not statistically significant ( $p=0.92$ ). There was no difference between the two groups with respect to the proportion of subjects with new $\mathrm{Q}$ waves after the operation $(0.33$ and 0.36 for placebo and supplemented groups, respectively; $p=0.92$ ).

Thallium scans (Table IV). There were no significant differences between the groups before the operation or at the time of discharge with respect to either the severity or the extent of perfusion defects at rest or for the combined (severity $\times$ extent) score. As expected, a significant improvement in all these parameters was noted after CABG $(p \leq 0.002)$.

\section{Discussion}

As the primary hydrophobic, chain-breaking antioxidant, $\alpha$-tocopherol has attracted interest as an agent for limiting ischemia-reperfusion injury resulting from oxygen-derived free radicals. ${ }^{8,11,12,17}$ Studies of $\alpha$-tocopherol treatment (frequently combined with ascorbic acid) in isolated perfused animal hearts have consistently shown less functional, structural, and biochemical changes than in controls. ${ }^{24-26}$ In human studies, plasma and myocardial $\alpha$-tocopherol levels have been shown in some $e^{8,11,12,17}$ but not all studies ${ }^{7}$ to decrease during bypass. This fall may be prevented by supplementation. ${ }^{17}$ Supplementation also attenuated the rise in levels of plasma hydrogen peroxide $\left(\mathrm{H}_{2} \mathrm{O}_{2}\right)^{17}$ and the lipid peroxidation marker malondialdehyde during and immediately after CPB. ${ }^{9}$ Whether these effects were clinically significant was addressed in the present study, which showed that augmentation of patients' antioxidant reserves by supplementation with $\alpha$-tocopherol and ascorbic acid had no significant effect on markers of myocardial injury after uncomplicated CPB operations. The lower median for CK-MB area under the curve in the treated group, although not statistically significant, is of a magni- tude $(23.5 \%)$ to suggest a possible clinical effect in some patients.

The lack of a demonstrable protective effect in the present study cannot be attributed to low concentrations of $\alpha$-tocopherol. Although plasma levels and not tissue levels were measured, it is probable that the latter was raised albeit to a lesser degree. ${ }^{8}$ After surgery, plasma concentrations of $\alpha$-tocopherol fell by $70 \%$ in the supplemented group, but concentrations remained at or above normal levels (see Fig. 1). In contrast, concentrations in the placebo group fell to negligible levels within 3 hours of the operation. Although part of this decrease may be attributed to hemodilution, the observed changes far exceeded the effects of hemodilution. Part of the change may also be attributed to changes in plasma lipids. Because the bulk of the $\alpha$-tocopherol is carried by plasma lipoproteins, levels of the vitamin are highly correlated with total plasma lipid levels, ${ }^{7}$ which tend to fall in the postoperative period. Nevertheless, the data indicate a clear difference between the groups in the circulating levels of $\alpha$-tocopherol after surgery.

Studies in isolated perfused animal hearts ${ }^{24-26}$ suggest that the fall in antioxidant reserve may have exposed some patients to the risk of clinically significant myocyte injury in the postoperative period. CK-MB profiles were fairly similar in supplemented and placebo groups; however, the power of the performed test for CK-MB area under the curve (normalized data) was low (0.37), suggesting that the negative finding be interpreted with caution. It is therefore not possible to exclude a clinically significant benefit with certainty. The $23.5 \%$ lower median for CK-MB area under the curve in the supplemented group is suggestive of a clinically significant effect, although changes of less than $25 \%$ are unlikely to be of major functional or prognostic significance. It is possible that a larger clinical trial may detect a clinically and statistically significant effect. Earlier studies are not helpful in this respect. On the basis of their study of 18 patients, Ballmer and associates ${ }^{7}$ concluded that $\alpha$-tocopherol (and carotenoid) concentrations were of no major concern during and after cardiac operations. In another recent study involving use of $\alpha$-tocopherol supplementation or placebo in 28 patients with cardiac disease, Yau and colleagues 8 showed small but significant improvements in myocardial metabolism, ventricular function, and CK-MB release but concluded that these changes were not clinically significant for low-risk patients. 
Table IV. Extent and severity of cardiac defect before and after cardiac surgery as determined by Tl-201 scans

\begin{tabular}{|c|c|c|c|c|}
\hline \multirow[b]{2}{*}{ Parameter } & \multicolumn{2}{|c|}{ Placebo group $(n=18)$} & \multicolumn{2}{|c|}{ Supplemented group $(n=23)$} \\
\hline & Median & First, third quartile & Median & First, third quartile \\
\hline \multicolumn{5}{|l|}{ Extent $(\%)^{*}$} \\
\hline Pre & 14.0 & 2,28 & 18.0 & 7,40 \\
\hline Post & 4.5 & 4,14 & 3.0 & 1,29 \\
\hline \multicolumn{5}{|l|}{ Severity (score) } \\
\hline Pre & 3.0 & 1,6 & 3.0 & 2,10 \\
\hline Post & 1.0 & 0,3 & 2.0 & 1,7 \\
\hline \multicolumn{5}{|c|}{ Severity $\times$ extent (score) $\ddagger$} \\
\hline Pre & 28.0 & 4,190 & 36.0 & 16,420 \\
\hline Post & 9.0 & 0,34 & 9.0 & 1,273 \\
\hline
\end{tabular}

"Between-group comparison: $p=0.45$; changes with time (pre-post): $p=0.001$; group $\times$ time interaction: $p=0.98$.

HBetween group comparison: $p=0.09$; changes with time (pre-post): $p=0.001$; group $\times$ time interaction: $p=0.22$.

古etween group comparison: $p=0.12$; changes with time (pre-post): $p=0.002$; group $\times$ time interaction: $p=0.45$.

A note of caution may be added here. None of the patients in the present study had low levels of $\alpha$-tocopherol in the preoperative period; it is possible that preoperative deficiency of the antioxidant may have yielded different results. Second, the present group of patients undergoing $\mathrm{CABG}$ were subjected to relatively short periods of ischemia (median crossclamp time 43 minutes). Prolonged ischemic periods are more likely to be associated with oxidative stress. ${ }^{27}$ Third, although CK-MB is the traditional gold standard for the diagnosis of myocardial infarction, peak values may be misleading after cardiac surgery. ${ }^{28}$ We therefore combined CK-MB measurements with other myocardial indicators (electrocardiograms and Tl-201 scans). It is possible that the latter investigations may not have found significant group differences, because they are not sensitive indicators of perioperative free radical injury. They have also not been specifically validated in a cardiac surgical population. Interpretation of the QRS scoring was complicated by the baseline imbalance between the treatment and placebo groups, with the treatment group having more extensive damage before surgery. However, QRS scores increased by a similar extent in both the placebo and treatment groups, with no suggestion of a benefit from antioxidant supplementation.

The efficacy of high-dose ascorbic acid administration on myocardial reperfusion injury in human beings has been recently reported. Intravenous ascorbic acid (1 gm) 90 minutes before bypass followed by cardioplegic solutions containing ascorbic acid $(1 \mathrm{mmol} / \mathrm{L})$ significantly reduced the release of cardiac enzymes in patients with ischemic periods greater than 50 minutes. ${ }^{29}$ High doses of ascorbic acid $(250 \mathrm{mg} / \mathrm{kg})$ given intravenously before CPB and at aortic crossclamping significantly reduced serum malondialdehyde, CK-MB, and lactate dehydrogenase concentrations in the postoperative period. ${ }^{18}$ Cardiac output was significantly higher in the treated patients for the first 6 hours after the operation. $^{18}$ These two studies suggest that high doses of ascorbic acid may effectively scavenge free radicals during and after $\mathrm{CPB}$ and offer a measure of protection to the myocardium. No statistically significant effects were seen in the present trial, in which an effectively lower dose was used (1 gm orally 12 hours before the operation).

The lack of obvious benefit from antioxidant pretreatment in the present study is disappointing in the light of numerous animal studies that support the concept of ischemia-reperfusion injury amenable to protection by antioxidants. ${ }^{24-26}$ Whether this is due to species differences, differences in treatment regimens, or periods of induced ischemia is uncertain. In human studies, administration of drugs with known antioxidant activity may be confounding. Allopurinol, $\beta$-blockers, and calcium channel blockers (which were commonly administered before surgery) may independently contribute to the free radical scavenging defenses of the patients. ${ }^{8,10,13}$ Concomitant medications were similar in the patient groups, and drug-related effects are therefore unlikely to be a confounding factor in the present study.

In summary, extended supplementation with $\alpha$-tocopherol combined with ascorbic acid 12 hours before routine, uncomplicated cardiac surgery pre vented the depletion of the primary lipid-soluble antioxidant $\alpha$-tocopherol in plasma, but provided no additional protection to the myocardium over the standard surgical regimen. Further studies are re- 
quired to determine the possible benefit for patients with longer crossclamp times who are at greater risk of ischemia-reperfusion injury.

We thank Carlo Novello, BPharm, FSHP, Assistant Chief Pharmacist, and Robert Soszynski, Senior Pharmacist, for preparing the vitamin and placebo capsules; Mark Butterworth, ANMT, for acquiring and processing the thallium scans; Diana Battistutta, BSc (Hons), for statistical advice; and Deirdre Moran, RN, for coordinating the patients and sample collections. The vitamin $\mathrm{E}$ was a gift from Roche Products Pty. Ltd. (Australia).

\section{REFERENCES}

1. Sussman MS, Bulkley GB. Oxygen-derived free radicals in reperfusion injury. Methods Enzymol 1990;186:711-23.

2. Cohen MV. Free radicals in ischemic and reperfusion myocardial injury: Is this the time for clinical trials? Ann Intern Med 1989;111:918-31.

3. Rangan U, Bulkley GB. Prospects for treatment of free radical-mediated tissue injury. Br Med Bull 1993;49:700-18.

4. Del Nido PJ, Mickle DAG, Wilson GJ, et al. Evidence of myocardial free radical injury during elective repair of tetralogy of Fallot. Circulation 1987;76(Suppl):V174-9.

5. Ferreira R, Llesuy S, Milei J, et al. Assessment of myocardial oxidative stress in patients after myocardial revascularization. Am Heart J 1988;115:307-12.

6. Emerit I, Fabiani JN, Ponzio O, Murday A, Lunel F, Carpentier A. Clastogenic factor in ischemia-reperfusion injury during open-heart surgery: protective effect of allopurinol. Ann Thorac Surg 1988;46:619-24.

7. Ballmer PE, Reinhart WH, Jordan P, Bühler E, Moser UK, Gey KF. Depletion of plasma vitamin $C$ but not of vitamin $E$ in response to cardiac operations. J Thorac Cardiovasc Surg 1994;108:311-20.

8. Yau TM, Weisel RD, Mickle DAG, et al. Vitamin E for coronary bypass operations. J Thorac Cardiovasc Surg 1994; 108:302-10.

9. Barta E, Pechan I, Cornak V, Luknarova O, Rendekova V, Verchovodko P. Protective effect of alpha-tocopherol and Lascorbic acid against the ischemic-reperfusion injury in patients during open-heart surgery. Bratisl Lek Listy 1991;92:174-83.

10. Davies SW, Underwood SM, Wickens DG, Feneck RO, Dormandy TL, Walesby RK. Systemic pattern of free radical generation during coronary bypass surgery. Br Heart J 1990; 64:236-40.

11. Coghlan JG, Flitter WD, Clutton SM, Ilsley CDJ, Rees A, Slater TF. Lipid peroxidation and changes in vitamin $E$ levels during coronary artery bypass grafting. J Thorac Cardiovase Surg 1993;106:268-74.

12. Weisel RD, Mickle DA, Finkle CD, et al. Myocardial freeradical injury after cardioplegia. Circulation 1989;80(Suppl): III14-8.
13. Johnson WD, Kayser KL, Brenowitz JB, Saedi SF. A randomized controlled trial of allopurinol in coronary bypass surgery. Am Heart J 1991;121:20-4.

14. Tabayashi $K$, Suzuki $Y$, Nagamine $S$, Ito $Y$, Sekino $Y$, Mohri H. A clinical trial of allopurinol (Zyloric) for myocardial protection. J Thorac Cardiovasc Surg 1991;101:713-8.

15. Menasche P, Piwnica A. Free radicals and myocardial protection: a surgical viewpoint. Ann Thorac Surg 1989;47:93945.

16. Frei B, Stocker R, Ames BN. Antioxidant defenses and lipid peroxidation in human blood plasma. Proc Natl Acad Sci U S A 1988;85:9748-52.

17. Cavarocchi NC, England MD, O'Brien JF, et al. Superoxide generation during cardiopulmonary bypass: Is there a role for vitamin E? J Surg Res 1986;40:519-27.

18. Dingchao $\mathrm{H}$, Zhiduan $\mathrm{Q}$, Liye $\mathrm{H}$, Xiaodong $\mathrm{F}$. The protective effects of high-dose ascorbic acid on myocardium against reperfusion injury during and after cardiopulmonary bypass. Thorac Cardiovasc Surg 1994;42:276-8.

19. Dimirov NV, Meyer C, Giluland D, Ruppenthal M, Chenoweth W, Malone W. Plasma tocopherol concentrations in response to supplemental vitamin E. Am J Clin Nutr 1991; 53:723-9.

20. Niki E. Lipid antioxidants: how they act in biological systems. Br J Cancer 1987;55(Suppl VIII):153-7.

21. Buttenshaw RL, Ford CA. Rapid simultaneous analysis of $\beta$-carotene, retinol, and $\alpha$-tocopherol by high performance chromatography [abstract]. Clin Biochem Rev 1991;12:79.

22. Hindman NB, Schocken DD, Widmann M, et al. Evaluation of a QRS scoring system for estimating myocardial infarct size. V. Specificity and method of application of the complete system. Am J Cardiol 1985;55:1485-90.

23. Garcia EV, van Train K, Maddahi J, et al. Quantification of rotational thallium-201 myocardial tomography. J Nucl Med 1985;26:17-26.

24. Massey KD, Burton KP. $\alpha$-Tocopherol attenuates myocardial membrane-related alterations resulting from ischemia and reperfusion. Am J Physiol 1989;256:H1192-9.

25. Mickle DA, Li RK, Weisel RD, et al. Myocardial salvage with trolox and ascorbic acid for an acute evolving infarction. Ann Thorac Surg 1989;47:553-7.

26. Klein HH, Pick S, Lindert S, Nebendahl K, Niedmann P, Kreuzer $\mathrm{H}$. Combined treatment with vitamins $\mathrm{E}$ and $\mathrm{C}$ in experimental myocardial infarction in pigs. Am Heart $J$ 1989;118:667-73.

27. Ferrari R, Alfieri O, Curello S, et al. Occurrence of oxidative stress during reperfusion of the human heart. Circulation 1990;81:201-11.

28. Lee TH, Goldman L. Serum assays in the diagnosis of acute myocardial infarction. Ann Intern Med 1986;105:221-33.

29. Eddy L, Hurvitz R, Hochstein P. A protective role for ascorbate in induced ischemic arrest associated with cardiopulmonary bypass. J Appl Cardiol 1990;5:409-14. 